\title{
NSF ATE CREATE Renewable Energy Center
}

\section{Dr. Kathleen Alfano, College of the Canyons}

Dr. Kathleen Alfano is the director/PI of the NSF ATE CREATE Renewable Energy Center and has led the multi-college consortium CREATE (California Regional Consortium for Engineering Advances in Technological Education) since its development in 1996-1997. She currently serves on the National Academy of Sciences Committee on the Emerging Energy Workforce. She served as a program director and co-lead for the ATE Program at the National Science Foundation in Arlington, Va. in 2007-2008 and previously as dean of Academic Computing and Professional Programs and as a faculty member at College of the Canyons. Dr. Alfano has a Ph.D. from UCLA. 


\section{ASEE NSF Poster Session \\ NSF ATE Regional Center CREATE \\ NSF ATE grant \#1002653}

\section{Research and Education Activities:}

\section{Executive Summary: Major Accomplishments in 2012-2013}

- Submitted and was awarded a NSF supplemental grant (NSF 1239631) to conduct a Renewable Energy faculty Learning Exchange between top U.S. community college faculty and faculty in Australia and New Zealand. A national nominating application process was conducted in the Fall of 2012 and a team of approximately 18 faculty and administrators has been chosen. A site visit to TAFEs in four of the Australian states and a visit to geothermal fields and a polytechnic in New Zealand is scheduled for March of 2013. Learning Exchange products will include conference papers and presentation and on-line materials.

- Developed and disseminated curricula and workshops on the following subjects: PV Technical Sales; Incorporating wind and solar mathematics exercises using MatLab; Solar Monitoring using SCADA.

- High school renewable energy curricula was developed and tested at Lompoc High School and a regional workshop for high school and community college faculty is planned for April 2013.

- Kid Wind Teacher Workshops were presented at Central and Southern California locations for middle and high school teachers and the resulting pre and post evaluation data showed a high degree of improvement in teacher content knowledge and attitude toward wind energy curriculum and teaching.

- Kid Wind Student Regional Competitions were hosted with co-sponsorship from public schools and the wind industry and the highest performing student teams competed at the Kid Wind Student finals co-supported by CREATE, AWEA, industry and KidWind at the AWEA national conference in Atlanta, CA in June of 2012 and CREATE-trained teams won both the middle school and high school divisions. (Information is available at the Kid Wind site at: http://learn.kidwind.org/challenge/state/California).

- CREATE has collaborated with IREC and the Department of Energy Solar Training Network to co-host and/or sponsor workshops for community college and high school faculty on beginning and advanced solar curricula and to promote the continued NABCEP certification of CREATE faculty.

- CREATE is sponsoring a series of meetings to coordinate geothermal curriculum development in the California and Nevada regions and is planning to conduct a DACUM in 2013. 


\section{Description of Activities and Accomplishments:}

The goal of this ATE Regional Center is to address the demonstrated high demand for renewable energy technicians in southern and central California as a multi-County consortium. This four year grant proposal will allow the Center to complete objectives in five areas: 1) the development and refinement of modular in-class, on-line, and hybrid renewable energy curricula integrated into degree pathways concentrating on the areas of wind and solar photovoltaic and thermal technologies and energy efficiency and management that are tied to industry skills standards and certifications; 2) development and implementation of a technical teacher professional development program in renewable energy which will allow community college, high school teachers, and industry professionals recruited to be teachers to acquire the technical knowledge and certifications and pedagogical skills to teach renewable energy in their classrooms; 3 ) develop and implement a $2+2+2$ pathway through partnership with high schools and universities to allow students interested in renewable energy careers to have a defined career ladder with multiple exit points integrated with industry certifications and college certificate and degree attainment; 4) conduct continuous assessment and evaluation with imbedded targeted research of curricular and professional development strategies to ensure that student, faculty, and industry goals are attained; and, 5) disseminate both the products and the partnership process to maximize the impact both regionally and nationally.

\section{United States - Australia Renewable Energy and Green Skills Learning Exchange Project - Phase 1 - Building and Implementing the US-Australia Green Learning Exchange and Network}

\section{Project Summary}

\section{Intellectual Merit}

The goal of this U.S.-Australia Renewable Energy and Green Skills Learning Exchange project is to develop a community of technical educators to improve curricula and pedagogy by sharing best practices in the content, teaching, certifications, articulation and career pathways for the green skills in renewable energy disciplines in both the United States and Australia. Specific renewable energy technician-level disciplines to be targeted will include but not be limited to: solar photovoltaic and solar thermal, geothermal, energy efficiency and energy management, and wind turbine technology. The sector focus would allow the colleges and TAFEs to share curricula, share expertise and experience in building and sustaining renewable energy programs including developing standards and credentials, begin to develop joint professional development projects, share employer engagement strategies, to ultimately build technical knowledge for the benefits of the teachers, students, and programs. An online learning portal (the DOE NTER platform) will be used to share and disseminate curricula and other learning materials and provide the platform to create new curricula together, including a 3-D 
component. In addition, to the technical skills piece, there is also a policy component, which will be part of the discussions at the Institute and with policymakers in Canberra.

\section{Broader Impact}

The project will develop and implement a learning exchange that will include a Green Skill/Renewable Energy Program Institute and TAFE institute site visit in March 2013 by teams of three from selected exemplary renewable energy programs at community colleges in the U.S. The project has a broad level of support both in Australia and in the ATE community college community. The Australia committed partners include: the Technical and Further Education (TAFE) Directors Australia, Manufacturing Skills Australia, TAFE Development Centre in Victoria, Swinburne with the National Centre for Sustainability (Garry McDonald) and RMIT another TAFE / University in Victoria and Australian government's Department of Industry, Innovation, Science, Research, and Tertiary Education (DIIRSTE). NSF Centers CREATE and ATEEC have already begun developing lists of potential strong U.S. renewable energy faculty to supply to the NSF selection committee for the Institute attendee selection process. A broad dissemination plan including conference presentations, journal articles, and the development of an online community using the Department of energy NTER platform will allow broader impact well beyond the initial community college participants.

\section{Alignment of the Project with the NSF ATE CREATE Center's Goals}

This project fits well with the purpose of the NSF ATE Renewable Energy Center. The purpose of the NSF ATE CREATE Renewable Energy Center is to address the high demand for renewable energy technicians in California as a multi-County consortium through the development and refinement of modular in-class, on-line, and hybrid renewable energy curricula integrated into degree pathways concentrating on the areas of wind and solar photovoltaic and thermal technologies and energy efficiency and management that are tied to industry skills standards and certifications and the development and implementation of a technical teacher professional development program in renewable energy which will allow community college, high school teachers, and industry professionals recruited to be teachers to acquire the technical knowledge and certifications and pedagogical skills to teach renewable energy in their classrooms and to disseminate both the products and the partnership process to maximize the impact nationally. Some international funding was included in the original grant so that an initial effort could be included to assess if other countries' renewable energy practices and certifications could provide material for the further refinement of the emerging U.S. renewable energy standards. This project would greatly further this purpose for the NSF ATE CREATE Renewable Energy Center.

\section{Rationale for Australia Partnership}

This project plan is based on initial prework conducted by subaward partner Mindy Feldbaum under funding from an Australia fellowship and from multiple U.S. community college visits conducted by Australian partner Garry McDonald. The short paper written by Mindy Feldbaum for the Australia conference in September 2011 is attached as one of 
the Supplemental documents and explains the Green Skills Network and the findings that have formed the initial foundations for the approach chosen and engendered the partnerships already committed to the success of this project.

Australia is one of the few countries in the world that has abundant natural resources in almost every forms of renewable energy, including solar, wind, geothermal, and biofuels. The Green Skills Network project would allow a variety of technical programs in wind, solar, geothermal, and other key areas to participate. Although different policy drivers exist in the two countries, creating a low-carbon economy is complex and interconnected in nature, requiring new knowledge, capabilities, and partnerships that do not know geographic bounds. The US could learn from the challenges and opportunities of the implementation of the Green Skills Agreement, a statement of the commitment of the Australian and state and territory governments to work collaboratively with employer and employee representatives, the VET sector and community organizations to ensure that training in, and the delivery of, skills for sustainability is an integral part of all vocational education and training and is relevant to the needs of industry. Areas of proposed investigation include:

- developing national standards in skills for sustainability within the requirements of the national regulatory framework

- the upskilling of VET practitioners so they can provide effective training and facilitation in skills for sustainability

- - the strategic review of Training Packages (sets of nationally endorsed standards and qualifications for recognizing and assessing people's skills) to embed sustainability knowledge, skills and principles

- - implementing a transition strategy to re-skill vulnerable workers. The Australian Technical and Further Education (TAFE) system is an excellent partner for the U.S. public community college technical programs. TAFE is a government-owned and nationally operated system of colleges offering qualifications that are recognized and transferable internationally. The focus in TAFE is on hands-on, practical training with key competencies embedded in every course that are thought to be essential for people entering the workforce. Courses are developed in consultation with business and industry to ensure the skills are relevant and in demand. TAFE also provides a pathway to university education where Diploma graduates can receive up to one or two year's credit towards a related university degree, through a system of credit transfer arrangements established with universities across Australia.

Source:

www.deewr.gov.au/Skills/Programs/WorkDevelop/ClimateChangeSustainability/ Pages/GreenSkillsAgreement.aspx

Explanation of the Project Scope

The project will be conducted in two Phases, the attached budget and this proposal is for Phase I. Phase I will include 7 colleges visiting TAFE schools and exchanging information in Australia in March 2013 through TAFE site visits and a joint Learning Institute in Australia, the start of the virtual learning community, and several deliverables (see below). Phase II will entail the Australians visiting the US (to be funded by Australia), This will also Learning Institute in the US, 
site visits to US community colleges, and the complete build out of the virtual learning community.

Committed Australia Partners

Technical and Further Education (TAFE) Directors Australia, Manufacturing Skills Australia, TAFE Development Centre in Victoria, Swinburne with the National Centre for Sustainability (Garry McDonald) and RMIT another TAFE / University in Victoria and Australian government's Department of Industry, Innovation, Science, Research, and Tertiary Education (DIIRSTE). U.S. College Representation for Network: A selection criteria rubric will be developed by a committee consisting of NSF Program Officers; the NSF ATE CREATE Renewable Energy Center; and the Collaboratory to provide a careful and unbiased selection process. Seven community colleges with exemplary renewable energy programs will be chosen with each college being supported to bring three representatives

- Administrator/Leadership, faculty member, and student or an industry partner. The rationale for including institutional leadership is that administrative support is critical to implementing and institutionalizing renewable energy programs at a college and there is a direct linkage to the TDA Australia organization because its membership is made up the

TAFE Institute Directors, In addition to site visits to TAFE schools, the project participants will go to Australia's capitol. Canberra. to talk with governmental officials about policy issues. The rationale for student participation is that this life-changing event, will provide a deeper learning experience and align with the CREATE goal of improving access for more underrepresented groups in renewable energy careers. Having a faculty member as part of this group would align with CREATE's technical teacher professional development goals and would be critical to enhancing new curricula and other teaching and learning activities.

By booking travel costs as part of a group, the project is hoping to also leverage funds to include one representative from AACC.

Sector Focus

At least one college will be chosen in each of the following sectors:

* Solar

* Wind

* Energy Efficiency/Energy Management

* Geothermal

* other areas of interest: biofuels, nuclear, and sustainability

The sector focus would allow the colleges and TAFEs to share curricula, share expertise and experience in building and sustaining renewable energy programs including developing standards and credentials, begin to develop joint professional development projects focused on one area, share employer engagement strategies, to ultimately build technical knowledge for the benefits of the teacher, students, and programs. An online learning portal, preferably the DOE NTER platform, will be used to share and disseminate curricula and other learning materials and even provide the platform to create new curricula together, including a virtual component.

In addition, to the technical skills component, there is also a policy component, which will be part of the discussions at the Institute and with policymakers in Canberra. Other 
broad common themes that have emerged from the initial Collaboratory prework included in partner Mindy Feldbaum's Australia fellowship and from multiple community colleges that Australian Garry McDonald visited in the US, may also be the focus of the visits:

- Framework for Holistic, Integrated, and Systems level learning in across disciplines, competencies and trades

- Employer/Workforce Development Engagement and Strategies and Partnerships

- Embedding Sustainability Principles into Technical Training

- Upskilling and Reskilling the Workforce

- Transitioning the Workforce from Carbon Intense Industries to Clean Energy Industries

- Job Creation/Entrepreneurship, and Innovation in Small and Medium Enterprises

- $\quad$ Teacher Professional Development and Pedagogical Approach to sustainability

* Policies that Help Support a Skilled Workforce in a Low Carbon Economy The short paper Mindy Feldbaum wrote for the conference in September 2011 that explains the Green Skills Network and findings have formed the intial foundations for the approach chosen and the partnerships already committed to the success of this project.

Project Management

Dr Kathleen Alfano, PI and Director of CREATE will oversee the project implementation and budget, assist with the operation and selection for the Australia Institute and subsequent ATE PI meeting follow-up, conduct the internal evaluation with Dr. Daylene Meuscke and contract with the outside evaluator, Dr. Jean Sando, and oversee the main subawardee, the Collaboratory (Mindy Feldbaum). The Collaboratory is the main liaison with the Australia partners and will do the majority of work to arrange the visits and Australia Institute and the Green Skills Network. The Collaboratory will also be making and processing travel arrangements, and telecommunications clearly have to be part of the costs. Mindy Feldbaum's time and that of her project assistant will be used for setting up the visits, communication with the Australians, meeting with Australian embassy, content, and agenda of the Institute and visits, and developing and writing products, and at least one presentation coming out of this project.

Deliverables and Dissemination

- Individual Faculty and College Team Papers from Participating Community Colleges focusing on new partnerships created, new technical knowledge and curricula that can be integrated into current teaching practices, recommendations and other lessons learned

- 7 Student Papers focused on specific green skills collaboration impacts

- A Summary Report of Australian Visit and Institute will be distributed to NSF; the ATE Community; and the U.S.-Australia Green skills partners and available for download on the CREATE website 
- Presentation of Green Skills Project to NSF ATE Conference in Washington, $\mathrm{DC}$ in 2013

- $\quad$ Two webinars, one pre-visit and one post-visit to kick off virtual learning community

Evaluation

CREATE will develop and contract for both internal and outside evaluation with internal evaluation conducted by Dr. Daylene Meuscke and outside evaluation by Dr. Jean Sando.

\section{Application}

\section{United States-Australia Renewable Energy Learning Exchange and Network}




\section{How to Apply}

\section{* Eligibility Requirements}

Community Colleges: Your exemplary community college renewable energy program was nominated for the US-Australia Renewable Energy Learning Exchange and Network by a national committee, made up of experts in the field. Due to the nomination, the CREATE Center is requesting that your college complete the following application, for the most qualified and experienced college representative(s) to apply for this opportunity. Nominations do not guarantee selection so it is important that you read through the application carefully, filling out all applicable sections, and compiling the entire application with ALL required documents and signatures. Please note there will be no substitutions for the nominee and program if the dates are not suitable or if an emergency precludes your college representative from participating in the Renewable Energy Network.

Deadline for Submission: By Wednesday, October 10, 2012 submit this application and two letters of recommendations as specified in Part D. Early submissions are greatly appreciated. Please note that late or incomplete applications may not receive full consideration. Applicants will be notified of selection by October 19, 2012 via email and by the US postal service.

Submission: To complete the application, save this form as a MS Word or Rich Text Format (RTF) file. Add space, as needed as you input your responses. Electronic submission is required.

Submit a single complete package, all at the same time, and preferably in PDF format (Word and RTF documents will be accepted if electronic signatures are inserted for Part $\mathrm{E}$ Certification). Please email your completed application to: Dr. Kathleen Alfano, NSF CREATE Center Director, kathleen.alfano@canyons.edu.

If you experience problems with submission, please contact Gabrielle Temple, CREATE Center Project Manager at (661)3623024 or gabrielle.temple@canyons.edu.

Questions about Application: If you have questions about applying for the CREATE Renewable Energy Network, please email: Mindy Feldbaum, Renewable Energy Network Project Manager, mfeldbaum@thecollaboratoryllc.com or Lisa Hohenemser lhohenemser@thecollaboratoryllc.com or call 301578-8609. 
IMPORTANT NOTE TO APPLICANTS: If accepted into the CREATE Renewable Energy Network project, your application is a contractual agreement between you and CREATE. The contractual agreement will include deliverables and outcomes that are expected from participation in the Renewable Energy Network. In addition, there is a requirement to practice professional behavior during the Australian Learning Exchange. Failure to behave professionally could result in the termination of your participation. Keep a copy of your original application for your records; if you are accepted, your signature/certifications in Part E of this application will be binding.

\section{Part A: Contact information}

Name:

Title:

Name of Community College:

Work Address:

Work Phone:

Work Fax:

Work Email:

Home Address:

Home Phone:

Home Email:

\section{Part B: Education \& Work Experience}

\section{Educational Background:}

\begin{tabular}{|l|l|l|}
\hline \multicolumn{1}{|c|}{ Institution(s) } & Major/minor(s) \\
\hline Undergraduate: & & Year of graduation \\
\hline Graduate: & & \\
\hline
\end{tabular}


Work Experience:

\begin{tabular}{|c|c|c|}
\hline Name of Organization & Title, Responsibilities & Dates \\
\hline & \\
\hline & \\
\hline
\end{tabular}

\section{Part C: Applicant Questions}

Please fill out each question succinctly and keep each response to no more than 250300 words. The application questions section should total no more than 6 pages; answers must be single-spaced, 12-point font, and with 1" margins. Application questions that exceed 6 pages will not be read past the page limit.

\section{Part I - Professional Experience and Expertise}

1. Please describe the energy technology program that you are involved in at your college, particularly your specific involvement in the program. In the description, please state the courses that you teach or have taught in the past three years, innovations in your program, students served each year, and use student data for program improvement purposes.

2. List and describe any energy technology-related work experience in business and industry, and/or in other organizations.

3. Please describe the role employers play in the design and implementation of your courses/programs. Describe one example in detail.

4. Describe your leadership involvement in energy technology-related activities (work, community, regional, research, policy arena, etc.).

5. Describe what professional development activities you have participated in the last 35 years and give one example of a collaborative activity.

6. What do you consider your greatest professional accomplishment to date related to energy technology?

7. What do you consider as one of the greatest challenges today in preparing and education workers for the renewable energy field?

\section{Part II: Renewable Energy Network Opportunity and Outcomes}

Please fill out each question fully and keep each response to no more than 250-300 words. 
1. Describe how your professional experiences would contribute to the achievement of each of the CREATE Renewable Energy Learning Exchange and Network outcomes (see introduction for outcomes).

2. What are your expectations for the Renewable Energy Network and how will you use this experience to enhance your teaching methods and/or industry relationships?

3. What do you see the value of creating a Renewable Energy Learning Exchange and Network between the two countries and how would you contribute to the network and use the information shared on the network?

4. Please indicate briefly the topic(s) you would like to be addressed in the Renewable Energy Network that you feel will be most important for your professional development and for the transfer of energy technology knowledge directly to your community college classroom or to your work, in general.

\section{Part D: Criteria for Selection}

The applications will be evaluated on the strength of the community college program and proposed representative. It is important for all applicants to provide enough level of detail within page limits to give reviewers a strong understanding of the college's renewable energy programs and depth and breadth of expertise and experience of representatives in the sectors.

\section{Strength of Program}

\section{The following serve as the criteria:}

Strong and committed faculty members that have deep experience and expertise working with or in sector and has demonstrated energy technology leadership

Proven track record of working with industry to identify specific green skills and competency requirements and define the standards and assessments for employer and industry-relevant curriculum

Development and implementation of new and/or enhanced renewable energy industry career pathways to credentials, with intermediate certifications, that allow for multiple entry and exits that facilitates completion and a seamless articulation to the next level of education and employment

Strong facilitation of meaningful participation of employers to help define the program strategy and goals, provide resources to support education/training (such as equipment, instructors, funding, internships, or other work-based learning activities), provide assistance with program design, and where appropriate, hiring qualified students who complete related education and training programs.

Commitment to quality programming through the use of data for continuous improvement and accountability purposes

Commitment from institutional leadership for renewable energy programming and understanding of federal, state, and regional policy issues

Current and relevant technology for programs and current and updated course materials and content validated by industry

\section{Strength of Proposed Representative}


Selection of participants shall based on (but not be limited to) the following criteria

\section{- Education and Training:}

* Energy Technology: Associates degree*, baccalaureate degree, and/or industry-specific training* in an energy technology field (e.g., traditional/renewable energy, energy efficiency, transportation, engineering, other), or other related education.

\section{- Current Employment:}

* Full-time faculty teaching member or administrator at a community college and/or professional actively working in a leadership position in energy technology field or related industry.

- Extensive Work Experience:

* At least three years teaching community college level energy technology (or science, math, or related technology with energy-related application/concentration) or equivalent work experience in energy related field or related industry.

- Demonstrated Abilities:

* Demonstrated energy technology leadership (e.g., in education, work, research, issues)

* Demonstrated communication skills and teamwork skills

* Proven experience in developing and implementing energy technology curriculum

* Ability to collaborate and willingness to understand and respect different cultures and perspectives

Applicants shall submit two letters of recommendation from addressing any two of the selection criteria. These letters must reflect academic, employment or community experiences that relate to the energy technology field and highlight leadership and teamwork abilities of the representative. These letters must accompany the application package, not be sent separately.

\section{Part E: Certification}




\section{Applicant's Certification}

I certify that the information I have provided in this document is accurate. I understand that if I am chosen to participate in the CREATE US - Australia Renewable Energy Learning Exchange and Network, I will be representing both my organization and the NSF CREATE Center. This application is a contractual agreement and I shall commit to:

- Prepare for the US-Australia Renewable Energy Learning Exchange and Network by completing readings and assignments;

- Stay updated on travel guidelines and required documentation for the CREATE US Australia Renewable Energy Learning Exchange and Network (including required visa and passport);

- Adhere to standards of professional behavior during the Australian Learning Exchange;

- Participate in all group activities during the term of the project and complete any evaluation assessments.

\section{Following the Australia Learning Exchange:}

- Present information in two venues (locally, regionally, and/or nationally) about the CREATE Renewable Energy Network;

- Collaborate and write section of paper for inclusion in a peer-reviewed paper;

- Participate in at least two online virtual learning community meetings; and

- Provide feedback and formal evaluation information to CREATE on the impact of the Renewable Energy Network on teaching and learning (including student assessment and demographic information).

Name:

Signature: Date:

\section{Chancellor/President's Certification:}

I have reviewed [insert name 's] application to the CREATE USAustralia Renewable Energy Learning Exchange and Network and fully support his/her participation. I understand that during the upcoming school year my employee 1) will travel to Australia as part of a NSF Center team to exchange energy technician teaching practices with faculty in Australia; 2) will return to the U.S. and participate in a learning exchange with faculty across the U.S.; 3) might apply new teaching and learning strategies related to the project and appropriate to his/her teaching assignment and students, 4) provide the CREATE Center with aggregate, anonymous, demographic information on students impacted, and 5) present to colleagues and the field about the CREATE Renewable Energy Network.

Chancellor/President:

Date:

Contact information (phone and email):

Chancellor and Presidents: We welcome your questions about the CREATE U.S.-Australia Renewable Energy Learning Exchange. Please contact the NSF ATE CREATE Center Director and Principal Investigator for this project, Dr. Kathleen Alfano (kathleen.alfano@canyons.edu). 
CREATE endorses the principle of equal educational and employment opportunities for all people, regardless of race, color, sex, religion, ancestry, national origin, sexual orientation, age or non-job related handicap or disability. Furthermore, the Center does not discriminate on the basis of race, color, sex, religion, ancestry, national origin, sexual orientation, age or non-job related handicap or disability in the educational programs or activities it operates. Questions related to this notice should be directed to the Director of CREATE at 26455 Rockwell Canyon Road, Santa Clarita, CA 91355. 